\title{
IMPROVING DECISION MAKING IN PRODUCT MODULARIZATION BY GAME-BASED MANAGEMENT TRAINING
}

\author{
Persson, Magnus (1); \\ Hsuan, Juliana (2); \\ Kvysgaard Hansen, Poul (3) \\ 1: Chalmers University of Technology; \\ 2: Copenhagen Business School; \\ 3: Aalborg University
}

\begin{abstract}
To deal with the complexity caused by a constantly increasing need for product customization many companies have adopted a product modularization strategy. Product modularization has the potential to give benefits both in the design of products, in manufacturing as well as in the supply chain. But, it poses great challenges in its implementation, which includes complex decision-making that will affect the whole value-chain. The purpose of this paper is to describe how a game-based approach can be used for academic education, and management training, with the aim of improving decision-making in product modularization. This by visualizing, and practice, the complex interplay between product, manufacturing and supply chain architecture. The paper describes the development of the LEGO Exploratorium game set up, based on the LEGO minifigures, and how it has been used for both teaching engineering students and in company workshop. Using this game set up will increase companies' possibilities to develop modularized products that are designed for both efficient manufacturing and supply chain management.
\end{abstract}

Keywords: product modularization, Decision making, game-based training, Complexity, Organisation of product development

\section{Contact:}

Persson, Magnus

Chalmers University of Technology

Technology Management and Economics

Sweden

magper@chalmers.se 


\section{INTRODUCTION}

This paper focus on how companies can use game-based management training for improving their decision-making in adopting, and implementing, a product modularization strategy in the development and manufacturing of their products. It is well-known that many manufacturing companies are facing a constantly increasing need for product customization, this for being able to offer products that will fulfil specific customer needs (Magnusson and Pasche, 2014). However, global competition often pushes companies to offer these customized products at prices similar to what can be achieved by mass-produced products (Fuchs and Golenhofen, 2019). This puts pressure on companies to reduce both product development cost as well as development lead-time. But, the customization increases the product variety, adding complexity to companies' operations, both in product development, manufacturing as well as in their supply chain. To deal with this increasing complexity, together with the need for development cost and lead-time reduction, many companies have adopted a product modularization strategy (Jacobs et al., 2011). By dividing the product into modules with defined and standardized interfaces in between the different modules the customization is facilitated (Gershenson et al., 2003; Mikkola, 2007). These interfaces make it possible to mix and match the modules in different configurations (Baldwin and Clark, 1997). By this, benefits such as reduced product development lead-time and cost can be gained (Marion et al., 2015; Magnusson and Lakemond, 2017). By adopting a product modularization strategy, companies can get wide range of other benefits that are appearing in many different steps in a product's value-chain. For example, product modularization facilities commonality and re-use of components among different products as well as product variants (Baldwin and Clark, 1997), it also gives benefits in manufacturing (Piran et al., 2016). Previous research has also identified positive effects on supply chain performance (Zhang et al., 2019; Mikkola, 2003). In addition, the standardized interfaces and decoupled modules makes it easier to replace or upgrade one module in the product without causing disruptions in the surrounding modules (Seliger and Zettl, 2008), which means that product modularity can facilitate both product overhaul and repair. Since product modularity has the potential to give benefits in design of products and services, production set-ups, knowledge and supply chains (Sanchez, 2000), it poses great challenges to be implemented. Furthermore, product modularization efforts are generally experienced to be more costly (Engel et.al., 2017). Modularization might also have a negative effect on possibilities for product innovation (Fleming and Sorenson, 2001). Product modularity therefore calls for involvement of most different organizational functions, such as product development, manufacturing, after sales and marketing. Previous research has also shown that different organizational functions favour different module solutions (Persson and Åhlström, 2006). Moreover, research on game-based training, and simulation of modularization effects is limited. Therefore, there is a great need for developing ways to both simulate and visualize the effects of decision-making in product modularization. Hence, this paper will focus on the following research question: How can management decision-making in regard to product modularization be trained? Initially, the focus will be on academic educational settings but reflections regarding industrial training will be considered.

This paper is structured as follows. The next section provides the literature review on product modularization, complexity and game-based training. Next, the empirical set up of LEGO Exploratorium 2.0 and 3.0 are described. Finally, practical perspectives and conclusions are discussed, including a comparison of traditional and game-based approaches to modularization.

\section{PRODUCT MODULARIZATION, COMPLEXITY AND GAME-BASED TRAINING}

\subsection{Product modularization and complexity}

Herbert Simon linked the concept of modularization to the concept of complex systems. He defines the concept complex system in respect to the properties of such a system: "Roughly, by a complex system I mean one made up of a large number of parts that interact in a non-simple way. In such systems, the whole is more than the sum of the parts, not in an ultimate, metaphysical sense, but in the important pragmatic sense that, given the properties of the parts and the laws of their interaction, it is not a trivial matter to infer the properties of the whole. In the face of complexity, an in-principle reductionist may be at the same time a pragmatic holist" (Simon, 1962, p. 468). One of the critical aspects of complex 
systems is that the overall logic is not present at the time when a decision on how to move on has to be taken (Snowden and Boone, 2007).

The management of complexity can be implemented through modularization for organizing complex products and processes efficiently (Baldwin and Clark, 1997, 2000). Modularization has for a rather long time mainly been applied in new product development (Schilling, 2000; Mikkola, 2006; Mufatto, 1999; Sanchez and Mahoney, 1996), and in recent years also in the development of services (Voss and Hsuan, 2009; de Blok et al., 2014; Brax et al., 2017). However, modularization can also be used for organizing and managing processes (Sahaym et al., 2007). Adopting modularization can contribute to simplifying complex processes and supply chains, where different modules and interfaces are standardized so they can be recombined to achieve new process and supply chain configurations, without affecting the functionality of the entire system (Mikkola, 2003). In addition, modularization can also be used as a basis for designing organizations (Pan et al., 2007; Hoetker, 2006).

Modularity can be considered as being a design strategy that aims at understanding the degree to which components can be separated and recombined into new configurations (Jacobs et al 2007: Lau et al., 2007), and is conceptualized in terms of product architectures (that can range between integral and modular) and respective components and interfaces (Mikkola, 2006). Integral product architectures have more unique components linked with specific interfaces, with the aim of achieving craftsmanship and performance. In contrast, modular product architectures are mostly comprised of standard components linked through standardized interfaces, with the aim of achieving economies of scale (Mikkola, 2006). LEGO toys are prime example of modular products, as all the components can be separated and recombined.

There are many reasons why companies pursue modularization strategies. First, the concept of product modularization was extensively used in the development of physical products (Baldwin and Clark, 2000; Mikkola, 2006). By this companies can gain benefits such as for example increased product variety (Persson and Åhlström, 2006), cost savings due to economies of scale (Lau et al., 2007), customization and postponement along the supply chain (Mikkola \& Skjøtt-Larsen, 2004; Mikkola, 2007), task specialization (Jose and Tollenaere, 2005), component sharing (Fisher et al., 1999), establishment of routines (Voss and Hsuan, 2009), and more. In the last few years modularization has increasingly been applied in the development of services (Voss and Hsuan, 2009; de Blok et al., 2014). Although there is extensive research on benefits to gain from modularization the process of realizing these potential benefits of product modularization have been given less attention. Furthermore, research indicates that different organizational functions might favour different ways of managing product modularization and prioritization of modules and interface solutions. Sometimes this causes complex trade-offs that are not trivial to solve, but call for management involvement to make decisions on what to prioritize (Persson and Åhlström, 2013). Hence, adopting and implementing a product modularization strategy is a great challenge including a rather complex decision-making since it affects many different organization functions and the whole product life cycle and supply chain. Game-based training provides risk-free playing field enabling the simulation of various scenarios and strategic decisions. Participants are free to experiment a wide range of creative solutions without penalty, such as for instance: How much novelty can we incorporate in the product designs without sacrificing standardization? Can the current manufacturing process handle this change? If not, what has to change and at what cost? Do you need to find new suppliers? In this process the participants learn the costly consequences and challenges of modularity as well.

With the increased application of digitalization technologies, modularity thinking as a way to manage complexity has increasingly being adopted in other fields. One such area is on gaming and simulation with the purpose of education.

\subsection{Game-based training}

One way to simulate decision-making and its effects is by developing and use serious games. A serious game can be defined as any meaningful use of games whose primary mission is not to entertain (Zyda, 2005). Michael Schrage sees serious play in line with modelling, prototyping and simulation. He emphasizes that the fundamental phenomena involved in serious play remain the same: "Serious play is about improvising with the unanticipated in ways that create new value. Serious play includes any tools, technologies, techniques, or toys that let people improve how to play seriously with uncertainties", (Schrage, 2000). 
Using cases in teaching is an effective, but often too little used, way of teaching (Andersen and Schiano, 2014). Already 60 years ago Cohen and Rhenman (1961) described a number of different management games. By using cases the teacher gives the students and practitioners a possibility of testing the reality of managerial decision-making. Making a decision in reality often includes a great deal of challenges, such as having incomplete information and conflicting goals. This is exactly how the situation is for a company when adopting and implementing a product modularization strategy. Using a case, or serious game, creates a really good opportunity to explore which theories that are needed and their effects (Courtney et al., 2015). In addition, case teaching is also a good learning strategy that shifts from teacher-centred to student-centred activities (Courtney et al., 2015).

\section{THE EMPIRICAL SETUP}

As mentioned, the aim of this paper is to support academic education, and management training, in managing product modularization. However, the original background of the initiative was very different. The initiative was initiated as an EU-project addressing the challenges of increasing young talents interest in and awareness of the various aspects of manufacturing (ManuSkills, 2014). Lacking such interest and awareness among young people was from the EU Commission seen as a threat to the future development of the European manufacturing industry.

The ManuSkills project incorporated a number of experiments and one of these was named "The LEGO Exploratorium". The manufacturing domain in a cognitive frame can be seen as a number of resources (machines, technical processes, materials, information, financial means, and people) that are brought together to produce some kind of product. The combination of the resources is to determine the business success in both a short as well as longer time perspective. Essentially, the business success is determined by the decisions taken by the people involved in the specific manufacturing setup. This is the key driver in a game setting: To make decisions about all the parameters related to involved resources.

The game aspect is to choose among a number of options that are mainly derived from the actual manufacturing setup of LEGO. However, the focus of the game is reduced to be only the manufacturing of the LEGO Minifigure. This choice was made in order to make the manufacturing setup appealing to young people. The choice of product also allowed students access to a substantial amount of online real-life video materials that efficiently visualize the whole manufacturing process of the Minifigure. The main game challenge is to scale the production from only a few hundred thousand product per year to millions of products per year. In that respect the game setup replicates the actual development as seen at LEGO. The players do not engage in developing new products as these are simply determined by the actual products developed and manufactured by LEGO.

Though the product appeared to be very simple the experiences showed that the simple initiating problem (to produce 250,000 LEGO Minifigures) developed into complex problems after just two game rounds where increasingly advanced challenges were introduced. The setup was tested on 200+ high school students with convincing result in regard to support gaining insight into manufacturing challenges (Hansen et al., 2016).

\subsection{LEGO Exploratorium 2.0}

The continued effort of developing the updated version of the game setup has focused on application at college and university level. This effort has been organized as a co-creation process. From 2016 and forward the development has been driven by people with mechanical and manufacturing engineering background. Traditionally, the pedagogical approach of these areas has been to teach the various disciplines individually. However, these topics in mechanical and manufacturing engineering have changed and expanded. Besides the traditional mechanical and manufacturing engineering topics new areas include automation, digitalization, logistics, ecology, supply chain management, and many others. The further deepening of the individual disciplines and the emergence of new disciplines have led to challenges in teaching the integration of the disciplines, and this is where a game setup have significant advantages.

Given the co-creation approach the game has developed into several versions with different foci. The version 2.0 was aiming at bachelor and master engineering students. This version has a dominant focus on teaching modularization management (Hansen and Persson, 2016). Based on suggestions from the participating students the product focus has been expanded. Instead of the simple LEGO Minifigure the product for the game setup has been expanded to incorporate the whole series of the 
Collectable LEGO Minifigure. This product series was launched in 2010 and is still being produced. Each series contains 9-22 various LEGO Minifigures packed in non-transparent aluminium foil bags. In total 34 series have been launched with a total of 565 different variants of the Minifigure. Figure 1 illustrates the Series 1 of the collectable series.
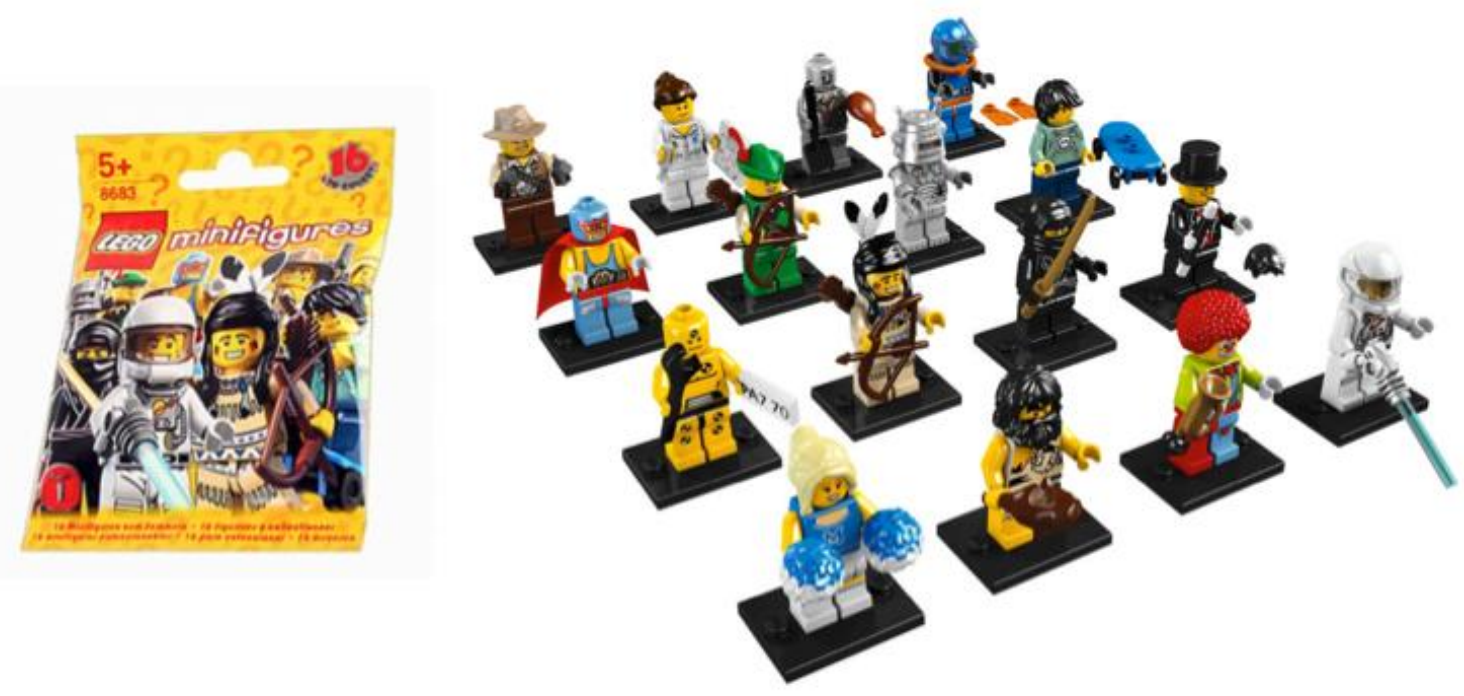

Figure 1. The LEGO collectable Minifigure Series 1, with the non-transparent bag (left) and the sixteen various LEGO Minifigures (right).

Each LEGO Minifigure is based on a modular product architecture that provides interfaces for different headgears (hairs, hats, head accessories) and different accessories to be attached to hands, legs, and body. The LEGO Minifigures come in a variety of colours and the decoration of head, upper body, lower body, arms, and accessories leads to a very high potential variety. The modular product architecture is followed by modular manufacturing process architectures (moulding, decoration, assembly and packaging) and modular supply chain architectures (sub-suppliers of all kinds). All product and process information are based on as "real" data as possible. That goes for product parts, material properties, mould design, machine properties, prices, etc. This makes it possible to go deep in some particular details, for example detailed analysis and simulation of the filling and cooling process of the injection moulding process of the various components.

The drivers of the game are open-ended challenges that include combined product, process and supply chain perspectives. These challenges are given in time windows that depend on the educational setup at the individual institutions. In some cases, the challenges are given on weekly basis and some more condensed setup lasting only 3 hours. The students respond to the given challenges by deciding on a specific setup of the manufacturing processes and the supply chain.

The first version of the game included a financial calculation based on a simple cost estimation. It was clear that this allowed for only limited discussion of the potential benefits of modularization. The cocreation process and the accompanying involvement of people with different competences made it possible to extend the financial dimension to include both an Income Statement and a Balance Sheet. This move made it possible to expand the discussion to also including investments, assets and depreciation.

\subsection{LEGO Exploratorium 3.0}

The most recent development of the game setup has taken place from 2018. It has become clear that the most powerful application of the game has been its ability to demonstrate the integration of the continuing specializing individual disciplines of mechanical and manufacturing engineering. Empirically it has been demonstrated that modular solution often performs lower on some parameters (e.g., higher cycle times for injections moulded components). The game allows to quantify the impact of such performance differences and to discuss under which specific circumstances different solutions might be superior. 
It has currently been applied in six engineering programmes. However, integration of disciplines is essentially what happens in the real life of industrial companies and, consequently, the game has been further developed to facilitate workshops in industrial companies. Until now three workshops have been conducted in industrial companies. It has also proven powerful in various types of management training efforts and have been applied in three MBA programmes. In terms of content, the setup has been expanded by including new financial evaluation option like the Net Present Value methodology. In 2019 a Discrete Event Simulation option was added. Elements of the game setup became integrated into the discrete event simulation software platform, Enterprise Dynamics.

\subsection{Practical implications and empirical findings}

Currently, the main application of the LEGO Exploratorium game setup is on teaching and company workshops focusing on modularization management. That is to support the understanding of how the combined modular product architecture, modular manufacturing process architecture and modular supply chain architecture need to be aligned to generate the modularization benefits.

Firstly, by amplifying this understanding in respect to making it explicit and quantifiable. Secondly, by coupling this understanding to specific decisions and following simulating how changes in the product and process configuration might impact the business performance. One specific example in the game setup is the introduction of $2 \mathrm{~K}$ (moulding simultaneously with two colours) and $3 \mathrm{~K}$ (moulding simultaneously with three colours) moulds in the production of the Minifigures. 2K moulding will allow to produce components with two colours of plastic. This will integrate the injection moulding process and the decoration process into one process. However, a financial positive effect is depending on a mix defined by a complex interplay between longer circle times, the investment in developing the solution, the lead time in developing solutions, the scalability of the solution, and the anticipated application areas of the solution.

Changes (as described above) can come from outside of the company in the form of competitor pressure, technology upgrade options, etc., or from inside of the company in the form of operations management decisions, technology development decisions, etc. The main reason for these opportunities in regard to strengthening the participants understanding of the details of modularization management lies in the product structure. The fact that the LEGO Minifigure is based on a modular product architecture that is one of the oldest and most powerful known modular product architectures is the key to the ability to support learning. In the following section, three empirical examples (two from academia and one from the company workshops) of the enhanced learning outcomes are presented.

\subsubsection{Uncertainties and commonality in the launch phase}

This application has been tested with $300+$ mechanical, manufacturing and industrial engineering students at master level. The focus is on the first three product launches of the LEGO Collectable Minifigure Series. Each series include 16 different Minifigures. The challenge is to establish a green field production. By choosing a green field setup it is possible to relate the technical and financial parameters to the Minifigure production only. Initially, only the final number of Minifigures for the first year is known. However, alternative scenarios that depend on the marked response to the initial launch are provided. It is requested that modularization benefits are made explicit.

The simple modular structure of the Minifigure makes it obvious that the basic structural component of the Minifigure (legs, arms, hands, upper body, head, hip) can be re-used. However, the realization of the benefits relies largely on the production and supply chain setup. The game setup allows the participants to choose between producing the parts or sourcing of the parts from external suppliers. All required specifications for the production equipment (machines, moulds, additional equipment) are provided and all prices are set as realistic as possibly. The same goes for prices of parts that are sourced from external suppliers. A substantial amount of publicly available video materials supports the participants in getting overview and insight into critical details in regard to both products and production technologies.

Normally, the participants are divided into teams of 2-3 persons in each. In each round the participants have to decide on strategy and investments and there is a strict timeline on when decisions have to be made. It is required that the strategy must be specific in respect to which effects and benefits to be realized. The steps of this application have typically been:

1. For the first round the production equipment in the form of injection moulding machines, moulds, decoration machines, and handling equipment is given. So, the first output is an income statement and a balance sheet for the first round. 
2. Based on the financial results, unit costs for the Minifigures are calculated. The importance of the sharing of the basic structural components are discussed and to some extent quantified.

3. Based on this, each team refines its strategy. They are given the plan for the launch of LEGO Collectable Minifigure Series 2 (16 new unique minifigures) and they have a fixed frame for new investments. This step results in significant differences between the teams. These differences emerge in the form of choice of new types of machinery, moulds and different strategies in regard to outsourcing.

4. The process is repeated for Series 3 .

5. Finally, the participants evaluate the whole process. They reflect upon the total result and make proposals for alternative setups that differs in respect to specific goals for modularization. In particular, they discuss the distinction between short-term and long-term financial performance.

\subsubsection{Impact of manufacturing technology development}

This application has been tested with 50+ manufacturing engineering students at master level. The application is typically done as an extension of the above-described application. The focus is on automation levels, integration, and scaling of manufacturing technology setup. In line with the empirical development at LEGO the sales number increases with new launches of the minifigure series. The increase in sales makes it relevant to consider a change in manufacturing setup. For the standard parts of the Minifigure it is relevant to consider a more efficient manufacturing setup, but it is clear that the high variety of accessories (head gear, tools, weapons, etc.) requires a differentiated manufacturing setup. In line with the empirically observed fact that LEGO does start to apply $2 \mathrm{~K}$ (moulding simultaneously with two colours) and $3 \mathrm{~K}$ (moulding simultaneously with three colours) moulding this aspect is also included in the game. The trade-off challenge is that these more advanced plastic injection moulds have longer cycle times which has to be counter-balanced by savings in respect to later parts of the internal value chain (e.g., decoration of the parts). Another aspect is the application of modular moulds. This allows for faster lead times and has different financial consequences.

Such aspects can normally only be understood at a high abstraction level. But the game setup allows the participants to formulate different scenarios and to evaluate these scenarios through Discrete Event Simulations. Thereby, it is possible to illustrate specific and quantifiable outcomes of the impact of the modular structure in both product and process.

\subsubsection{Analogy discussions in comparison to an industrial company}

This application is run as workshops and has been tested in three industrial companies from different industries (industrial ventilation, offshore, and building). The duration has typically been 4-6 hours with involvement of participants from both the product development and production functions in the company. The workshops combine a focus on the product portfolio of the company and the game. In all cases the product structure of the products in focus is far as modular as the Minifigure. However, it has proven that the modular LEGO product can serve as a visionary reference.

In the three cases the focus has primarily been on developing a modularization vision. The impact of applying the game setup has been a strong support to defining the specific goals and to give a realistic bid on how the benefits will emerge in respect to the planned strategic efforts. In particular, the clarification of which decisions that need to be taken and the connection between these have been supported by the game process.

\section{PERSPECTIVES AND CONCLUSION}

The purpose of this paper has been to describe how a game-based approach can be used for academic education, and management training, with the aim of improving the complex decision-making in product modularization. This game can be used for training by simulating the complex interplay between the product, the manufacturing process and the supply chain architecture that all will be affected by product modularization, but also affecting its implementation. From our experiences in practicing and teaching modularization, the most important observations and the implications for supporting an extended understanding of modularization management with the application of the LEGO Exploratorium setup are listed in Table 1. This is based on the preliminary results of approximately 15 workshops over three years. 
Table 1. Differences between traditional teaching approach and game-based approach

\begin{tabular}{|c|c|c|}
\hline Topic & Traditional Approach & Game-Based Approach \\
\hline Modularization benefits & $\begin{array}{c}\text { Focusing on reuse at } \\
\text { component level and making } \\
\text { quantitative estimations }\end{array}$ & $\begin{array}{r}\text { The time element in the game } \\
\text { makes it possible to } \\
\text { additionally include lead-time } \\
\text { and capital binding aspects }\end{array}$ \\
\hline $\begin{array}{l}\text { Financial modularization } \\
\text { benefits }\end{array}$ & $\begin{array}{l}\text { Unit cost calculations based on } \\
\text { scaling }\end{array}$ & $\begin{array}{r}\text { Combined unit cost } \\
\text { calculations, depreciation } \\
\text { polities and practice, liquidity, } \\
\text { NPV }\end{array}$ \\
\hline Modularization drivers & $\begin{array}{l}\text { Listing various modularization } \\
\text { drivers and providing } \\
\text { qualitative cases }\end{array}$ & $\begin{array}{r}\text { Letting participants choose } \\
\text { relevant modularization drivers } \\
\text { and quantifying impact in } \\
\text { financial terms }\end{array}$ \\
\hline $\begin{array}{l}\text { Modularization management } \\
\text { decisions }\end{array}$ & $\begin{array}{l}\text { The complexity dimensions of } \\
\text { the needed decisions are hard } \\
\text { to illustrate. Therefore, the } \\
\text { decisions are experienced one- } \\
\text { dimensional }\end{array}$ & $\begin{array}{r}\text { The time aspect illustrates that } \\
\text { decisions are to be taken with } \\
\text { limited knowledge about the } \\
\text { future }\end{array}$ \\
\hline $\begin{array}{l}\text { Modularization benefit } \\
\text { horizons }\end{array}$ & $\begin{array}{l}\text { A few relations between short } \\
\text { term and long-term benefits } \\
\text { can be illustrated by cases }\end{array}$ & $\begin{array}{r}\text { Specific exemplification of } \\
\text { differences between short term } \\
\text { and long-term benefits. The } \\
\text { inclusion of the balance sheet } \\
\text { quantifies this insight }\end{array}$ \\
\hline
\end{tabular}

It has been argued that case teaching is a very effective way of teaching (Andersen and Schino, 2014), and that this learning strategy is a good way to shift from teacher-centred to student-centred activities (Courtney et al., 2015). Using the LEGO Exploratorium provides a risk-free playing field enabling the simulation of various scenarios, and practical implications of strategic decisions. The game also shows how important modularization decisions affect different organizational functions, and different steps in the product life cycle and supply chain. This increased understanding gives possibilities for companies to learn to develop modularized products and product variants, that are designed for both efficient manufacturing as well as efficient supply chain design and management.

\section{ACKNOWLEDGMENTS}

The research leading to these results has received funding from the European Community's Seventh Framework Programme (FP7/2007-2013) under grant agreement no. 609147.

\section{REFERENCES}

Andersen, E. and Schiano, B. (2014). Teaching with Cases. Harvard Business School Publishing.

Baldwin, C.Y. and Clark, K.B. (1997), "Managing in an age of modularity", Harvard Business Review, Vol. 75 No. 5, pp. 84-93.

Baldwin, C.Y., Clark, K.B., 2000. Design Rules. MIT Press, Cambridge, Mass.

Brax, S.A., Bask, A., Hsuan, J. and Voss, C. (2017), "Service modularity and architecture: an overview and research agenda", International Journal of Operations \& Production Management, Vol. 37 No. 6, pp. 686702. https://doi.org/10.1108/IJOPM-03-2017-0191

Cohen, K.J. and Rhenman, E. (1961). "The role of management games in education and research", Management Science", Vol. 7, No. 2, pp. 131-166.

Courtney, N., Poulsen, C. and Stylios, C. (2015), Case Based Teaching and Learning for the $21^{\text {st }}$ Century. Libri Publishing, Oxfordshire, UK.

de Blok, C., Meijboom, B., Luijkx, K., Schols, J. and Schroeder, R. (2014), "Interfaces in service modularity: a typology developed in modular health care provision”, Journal of Operations Management, Vol. 32, pp. 175-189. https://doi.org/10.1016/j.jom.2014.03.001

Engel, A., Browning, T. R. and Reich, Y. (2017). "Designing products for adaptability: insights from four industrial cases", Decision Sciences, Vol. 48, No. 5, pp. 875-917. https://doi.org/10.1111/deci.12254 
Fisher, M., Ramdas, K. and Ulrich, K. (1999), "Component sharing in the management of product variety: a study of automotive braking systems", Management Science, Vol. 45 No. 3, pp. 297-315. https://doi.org/10.1287/mnsc.45.3.297

Fleming, L. and Sorenson, O. (2001), “The Dangers of Modularity”, Harvard Business Review, Vol. 79, No. 8, pp. 20-21.

Fuchs, C. and Golenhofen, F. (2019). Mastering Disruption and Innovation in Product Management. Springer International Publishing.

Gershenson, J.K., Prasad, G.J. and Zhang, Y. (2003), "Product modularity: Definitions and benefits", Journal of Engineering Design, Vol. 14 No. 3, pp. 295-313. https://doi.org/10.1080/0954482031000091068

Hansen, P.K. and Persson, M. (2016), "Engineering Case Method Applied in Teaching Modularization Management", DS 85-2: Proceedings of NordDesign 2016, Volume 2, Trondheim, Norway, 10th - 12th August 2016, Boks, C., Sigurjonsson, J., Steinert, M., Vis, C., and Wulvik, A. (Eds.), Educational Perspectives.

Hansen, P.K., Oliveira, M. and Costa, J. (2016), "Co-design of a game to support increased manufacturing insight and interest among teenagers and young adults", Games and Learning Alliance: 4th International Conference, GALA 2015, Rome, Italy, December 9-11, 2015, Revised Selected Papers. Gloria, A. D. \& Veltkamp, R. (red.), Springer, pp. 421-430.

Hoetker, G. (2006), “Do modular products lead to modular organizations?”, Strategic Management Journal, Vol. 27, pp. 501-518. https://doi.org/10.1002/smj.528

Jacobs, M., Vickery, S.K. and Droge, C. (2007), "The effects of product modularity on competitive performance. Do integration strategies mediate the relationship?" International Journal of Operations and Production Management, Vol. 27 No. 10, pp. 1046-1068. https://doi.org/10.1108/01443570710820620

Jacobs, M., Droge, C., Vickery, S.K. and Calantone, R. (2011), "Product and process modularity's effects on manufacturing agility and firm growth performance", Journal of Product Innovation Management, Vol. 28 No. 1, pp. 123-137. https://doi.org/10.1111/j.1540-5885.2010.00785.x

Jose, A. and Tollenaere, M. (2005) "Modular and platform methods for product family design: literature analysis", Journal of Intelligent Manufacturing, Vol. 16, pp. 371-390.

Lau, A.K.W., Yam, R.C.M. and Tang, E.P.Y. (2007), "Supply chain product co-development, product modularity and product performance. Empirical evidence from Hong Kong manufacturers", Industrial Management and Data Systems, Vol. 107 No. 7, pp. 1036-1065. https://doi.org/10.1108/02635570710816739

Magnusson, M. and Pasche, M. (2014), "A contingency-based approach to the use of product platforms and modules in new product development”, Journal of Product Innovation Management, Vol. 31 No. 3, pp. 434-450. https://doi.org/10.1111/jpim.12106|

Magnusson, T. and Lakemond, N. (2017), "Evolving schemes of interpretation: Investigating the dual role of architectures in new product development", $R \& D$ Management, Vol. 47 No. 1, pp. 36-46. https://doi.org/10.1111/radm.12142|

ManuSkills EU Project (2014), Envisioning an advanced ICT-supported build-up of manufacturing skills for the Factories of the Future, FoF-ICT-2013.7.2, Grant agreement no. 609147.

Marion, T.J., Meyer, M.H. and Barczak, G. (2015), "The influence of digital design and IT on modular product architecture", Journal of Product Innovation Management, Vol. 32 No. 1, pp. 98-110. https://doi.org/10.1111/jpim.12240|

Mikkola, J.H. (2003), "Modularity, component outsourcing, and inter-firm learning”, R\&D Management, Vol. 33 No. 4, pp. 439-454. https://doi.org/10.1111/1467-9310.00309

Mikkola, J.H. (2006), "Capturing the degree of modularity embedded in product architectures", Journal of Product Innovation Management, Vol. 23 No. 2, pp. 128-146. https://doi.org/10.1111/j.15405885.2006.00188.x

Mikkola, J.H. (2007), "Management of product architecture modularity for mass customization: Modeling and theoretical considerations”, IEEE Transactions on Engineering Management, Vol. 54 No.1, pp. 57-69. https://doi.org/10.1109/TEM.2006.889067

Mikkola, J.H. and Skjøtt-Larsen, T. (2004), "Supply Chain integration: Implications for mass customization, modularization and postponement strategies", Production Planning and Control, Vol. 15 No. 4, pp. 352361. https://doi.org/10.1080/0953728042000238845

Muffatto, M. (1999), "Platform strategies in international new product development", International Journal of Operations and Production Management, Vol. 1 No.5/6, pp. 449-459.

https://doi.org/10.1108/01443579910260766

Pan, S.L., Pan, G., Chen, A.J.W. and Hsieh, M.H. (2007), "The dynamics of implementing and managing modularity of organizational routines during capability development: Insights from a process model", IEEE Transactions on Engineering Management, Vol. 54 No. 4, pp. 800-813. https://doi.org/10.1109/TEM.2007.906854

Persson, M. and Åhlström, P. (2006), "Managerial issues in modularising complex products", Technovation, Vol. 26 No. 11, pp. 1201-1209. https://doi.org/10.1016/j.technovation.2005.09.020 
Persson, M. and Åhlström P. (2013), "Product Modularization and Organizational Coordination", International Journal of Automotive Technology and Management, Vol. 13 No. 1, pp. 55-74.

Piran, F.A.S., Lacerda, D.P., Camargo, L.F.R., Viero, C.F., Dresch, A. and Cauchick-Miguel, P.A. (2016), "Product modularization and effects on efficiency: An analysis of a bus manufacturer using Data Envelopment Analysis (DEA)”, International Journal of Production Economics, Vol. 182, pp. 1-13. https://doi.org/10.1016/j.ijpe.2016.08.008

Sahaym, A., Steensma, H.K. and Schilling, M.A. (2007), "The influence of information technology on the use of loosely coupled organizational forms: An industry-level analysis”, Organization Science, Vol. 18 No. 5, pp. 865-880. https://doi.org/10.1287/orsc.1070.0285

Sanchez, R. (2000), "Product and process architectures in the management of knowledge", in Robertson \& Foss (Eds.), Resources, Technology and Strategy. Routledge, London.

Sanchez, R. and Mahoney, J.T. (1996), "Modularity, flexibility, and knowledge management in product and organization design”, Strategic Management Journal, Vol. 17, pp. 63-76. https://doi.org/10.1002/smj.4250171107

Schrage, M. (2000), Serious Play - How the World's Best Companies Simulate to Innovate. Harvard Business School Press.

Schilling, M.A. (2000), "Toward a general modular systems theory and its application to interfirm product modularity," Academy of Management Review, Vol. 25 No. 2, pp. 312-334. https://doi.org/10.5465/amr.2000.3312918

Seliger, G. and Zettl, M. (2008). "Modularization as an enabler for cycle economy", CIRP Annals Manufacturing Technology, Vol. 57, pp. 133-136. https://doi.org/10.1016/j.cirp.2008.03.031

Simon, H.A. (1962), "The Architecture of Complexity", Proceedings of the American Philosophical Society, Vol. 106 No. 6, pp. 467-482.

Snowden, D.J. and Boone, M. (2007), “A Leader's Framework for Decision Making”, Harvard Business Review, November, pp. 68-76.

Voss, C.A. and Hsuan, J. (2009), "Service architecture and modularity”, Decision Sciences, Vol. 40 No. 3, pp. 541-569. https://doi.org/10.1111/j.1540-5915.2009.00241.x

Zhang, M., Guo, H., Huo, B., Zhao, X. and Huang, J. (2019), "Linking supply chain quality integration with mass customization and product modularity", International Journal of Production Economics, Vol. 207 pp. 227-235. https://doi.org/10.1016/j.ijpe.2017.01.011

Zyda, M. (2005), "From visual simulation to virtual reality to games", Computer, Vol. 38 No. 9, pp. 25-32. https://doi.org/10.1109/MC.2005.297 